\title{
Co-infections associated with human immunodeficiency virus type 1 in pregnant women from southern Brazil: high rate of intraepithelial cervical lesions
}

\author{
Michele Tornatore' ${ }^{1}$, Carla Vitola Gonçalves ${ }^{1}$, Mônica Steigleder Bianchi' \\ Fabiana Nunes Germano ${ }^{2}$, Alzira Xavier Garcés ${ }^{1}$, Marcelo Alves Soares ${ }^{2,3} /{ }^{+}$, \\ Elizabeth Stankiewicz Machado ${ }^{2}$, Ana Maria Barral de Martinez ${ }^{1}$
}

Faculdade de Medicina, Universidade Federal do Rio Grande, Rio Grande, RS, Brazil ²Departamento de Genética,
Centro de Ciências da Saúde, Universidade Federal do Rio de Janeiro, Av. Mal. Trompowsky s/n Bloco A 20 andar,
21941-570 Rio de Janeiro, RJ, Brazil ${ }^{3}$ Programa de Genética, Instituto Nacional de Câncer, Rio de Janeiro, RJ, Brazil

Human immunodeficiency virus type 1 (HIV-positive) pregnant women require specific prophylactic and therapeutic approaches. The efficacy of established approaches is further challenged by co-infection with other sexually transmitted diseases (STDs). The objective of this study was to determine the prevalence of co-infections in pregnant women infected with different HIV-1 subtypes and to relate these findings, together with additional demographic and clinical parameters, to maternal and infant outcomes. Blood samples from pregnant women were collected and tested for syphilis, hepatitis B virus (HBV) and hepatitis C virus (HCV). Human papillomavirus (HPV) diagnosis was evaluated by the presence of alterations in the cervical epithelium detected through a cytopathological exam. Medical charts provided patient data for the mothers and children. Statistical analyses were conducted with STATA 9.0. We found a prevalence of $10.8 \%$ for $\mathrm{HCV}, 2.3 \%$ for chronic $\mathrm{HBV}, 3.1 \%$ for syphilis and $40.8 \%$ for HPV. Of those co-infected with HPV, $52.9 \%$ presented high-grade intraepithelial lesions or in situ carcinoma. Prematurity, birth weight, Apgar 1' and 5' and Capurro scores were similar between co-infected and non-co-infected women. The presence of other STDs did not impact maternal and concept outcomes. More than half of the patients presenting cervical cytology abnormalities suggestive of HPV had high-grade squamous intraepithelial lesions or cervical cancer, evidencing an alarming rate of these lesions.

Key words: pregnancy - HIV-1 - co-infections - STDs - cervical carcinoma

According to the latest UNAIDS epidemiological report, 33 million people are infected with the human immunodeficiency virus (HIV) worldwide. Among them, 18 million are women and two million are children between zero-14 years of age (WHO 2010). In Latin America, Brazil is one of the countries most affected by the acquired immunedeficiency syndrome (AIDS), harbouring over 500,000 registered cases at the end of 2009. Early in the epidemic, the man-to-woman infection ratio was $40: 1$; by June 2008 , this difference had been reduced to $1.3: 1$. This proportion is inverted for cases between ages of 13-19, where 10 girls are infected with HIV for every six boys (MS 2010a).

By 2010, in Rio Grande, a city driven by harbour and university activities and with a population of approximately 200,000 inhabitants, 1,382 cases of AIDS have been reported, making it one of the top 10 most-affected cities in the state of Rio Grande do Sul (RS), the south-

Financial support: CNPq (300475/2005-5 to ESM), CAPES (01990052 to AMBM and MAS), MS Brazil (107/2006 to MAS and ESM)

+ Corresponding author: masoares@inca.gov.br

Received 5 June 2011

Accepted 10 October 2011 ernmost state of Brazil (MS 2010a). Among the reported cases, 551 were in women and 61 were in children younger than 14 years of age.

Pregnant women infected with HIV-1 receive tailored prophylactic and therapeutic approaches, as established by international and country-based guidelines. However, the efficacy of those approaches can be compromised when the patient is co-infected with other viruses, such as with hepatitis B virus (HBV), hepatitis C virus (HCV), human papillomavirus (HPV) or with bacteria such as Treponema pallidum, the etiological agent of syphilis. As HIV-1 and other pathogens share some or all transmission routes, the occurrence of co-infections is frequent. Among all those infected with HIV in the world, it is estimated that approximately $10 \%$ are co-infected with HBV and approximately $15 \%$ with HCV (Alberti et al. 2005, Soriano et al. 2006). It has been suggested that HIV-1/HCV co-infection of pregnant women increases the rate of mother-child transmission of HCV to their infants (Polis et al. 2007). Syphilis also displays increased prevalence among HIV-1-infected pregnant women. The disease may result in miscarriage/abortion, intrauterine and neonatal death or severe sequelae to the newborn. HIV-1-positive pregnant women co-infected with syphilis have a higher risk of vertically transmitting HIV-1 and the course of syphilis may also be altered during co-infection (Mwapasa et al. 2006, Thorne et al. 2008). In co-infected patients, the recommended therapeutic 
schemes for both syphilis and HIV might not be as effective as in mono-infected patients (MS 2010b). Lastly, HPV is another relevant infection concerning women. HPV is a virus associated with cervical cancer that is sexually transmitted and studies indicate that women infected by HIV-1 have a higher prevalence of HPV infection, as well as a greater risk of developing cervical cancer (Franceschi \& Jaffe 2007).

It has been suggested that the genetic diversity of HIV-1 leads to different clinical manifestations of the infection, such as different times of progression to disease (Kiwanuka et al. 2008), susceptibility to antiretrovirals (Poveda et al. 2008) and transmissibility (Renjifo et al. 2004). In Rio Grande, HIV-1 subtypes B and C are equally predominant (Soares et al. 2005). Therefore, the objective of this study was to determine the prevalence of co-infections associated with infections by different HIV-1 subtypes among pregnant women followed-up at University Hospital of Rio Grande, RS. We also describe demographic factors, antiretroviral responses and maternal and neonatal outcomes in this HIV-positive pregnant women cohort.

\section{PATIENTS, MATERIALS AND METHODS}

This was a cross-sectional study carried out with HIV-1-infected pregnant women followed between July 2006-December 2008 at the HIV/AIDS service of Hospital Universitário Dr Miguel Riet Corrêa Jr, Federal University of Rio Grande (FURG).

The presence of antibodies for HBV and HCV was evaluated with commercial enzyme-linked immune sorbent assay methods. A diagnosis for HBV was considered positive if the patient was HBsAg-reactive (confirmed with anti-HBc reactivity). Patients with a positive anti-HCV test were considered to be infected with HCV. For the diagnosis of HPV infection, colpocytologic exam results were collected during antenatal care. For the diagnosis of syphilis, the results of VDRL exams were used. A positive diagnosis was considered for patients with a titre $\geq 1: 1$.

The maternal HIV-1 subtype was determined through proviral DNA detection by polymerase chain reaction (PCR) in DNA samples extracted from total blood with an Illustra ${ }^{\circledR}$ Blood Genomic Prep Mini Spin Kit (GE Healthcare). A nested PCR was performed to amplify the immunodominant region of the viral gp41 gene. The primers used in this reaction were as follows: JH38 (5'CAGCAGGAAGCACTATGGG3') and JH41 (5'GGTGAGTATCCCTGCCTAAC3') for the first amplification round and Menv27 (5'AAGCCTCCTACTATCATTATGA3') and Env19 (5'CTGGTATAGTGCAACAG CA3') for the second round. Sequencing was performed in an ABI Prism 3100 system (Applied Biosystems, Foster City, USA) and the reactions were performed according to the manufacturer's suggested protocol. Sequences were edited with the Lasergene software package (DNAStar Inc, Madison, USA) and were aligned with the CLUSTALW program. Additional reference sequences obtained from the Los Alamos HIV sequence database (hiv-web.lanl.gov) were included in the alignment. A phylogenetic analysis using the neighbour- joining method and the Kimura two-parameter correction was carried out with all sequences to determine their HIV-1 subtype by grouping with reference sequences. The phylogenetic inference was conducted using MEGA 4.0 software (Tamura et al. 2007). The robustness of the different clades in the tree was evaluated by bootstrapping with 2,000 replications in MEGA.

The $\mathrm{CD} 4^{+} \mathrm{T}$ cell counts of patients were determined by flow cytometry in a BD FacsCount ${ }^{\circledR}$ System and HIV-1 viral load quantification was performed using a Versant ${ }^{\circledR}$ test (Bayer Diagnostics, EUA) using blood samples of the mothers collected at week 34 of gestation. Some demographical factors were also analysed, such as age, race and level of education. For the maternal outcomes, prematurity $(<37$ weeks) and time of membrane rupture ( $\leq$ or $>4 \mathrm{~h})$ were evaluated. The following variables were evaluated from the infants: birth weight, Apgar score for the first and fifth minutes and Capurro score. Data were analysed using the chisquared test for categorical variables and the Student's $t$ test for continuous variables.

Ethics - Patients signed an informed consent form to participate in the study and the study was submitted and approved by the FURG's Ethical Committee (protocol 23116001368/2003-44). All procedures were carried out in accordance with the guidelines of the Helsinki Declaration.

\section{RESULTS}

One-hundred and thirty women infected by HIV-1 were followed-up at the antenatal service at FURG's specialised ambulatory clinic between July 2003-December 2008. The mean age of these patients was 26.2 $( \pm 5.69)$ years. Ninety-eight $(75.4 \%)$ of the patients were white and $32(24.6 \%)$ were afro-descendants or mestizos. Ninety-six patients $(73.8 \%)$ had completed eight years of education.

Three patients $(2.3 \%)$ presented a positive $\mathrm{HBsAg}$ reactive test and $14(10.8 \%)$ had a positive anti-HCV test. All three HBV-positive patients were simultaneously infected by HCV. Four patients (3.1\%) presented a VDRL-reactive test during follow-up. With respect to cytopathological exams, 53 (40.8\%) presented cellular alteration, indicating the presence of HPV. Of these, eight (15.1\%) presented koilocytosis, 17 (32\%) had lowgrade lesions and 28 (52.8\%) presented high-grade cervical lesions (HSILs) or in situ carcinoma (Table I).

HIV-1 viral subtype was determined in 105 cases. Seventy-five women (71.4\%) carried HIV-1C infections and $30(28.6 \%)$ had HIV-1B. Data on co-infections were available for 98 patients in this group: $39(78 \%)$ of co-infected women harboured HIV-1C, whereas $11(22 \%)$ had HIV-1B. This difference was not statistically significant $(p=0.14)$.

The average $\mathrm{CD}^{+} \mathrm{T}$-cell lymphocyte count among the co-infected pregnant women was $563.7 \pm 323.6$ cells and among those non-co-infected it was $632.5 \pm 372.2$ cells $(p=0.25)$. Among those infected by different HIV-1 subtypes, the average count was $700 \pm 335$ cells among those with HIV-1B and $547 \pm 340$ cells among those with HIV-1C $(p=0.04)$. With respect to the HIV-1 viral load, the mean $\log 10$ was 1.54 among those co-infected 
and 0.97 among those without a co-infection $(\mathrm{p}=0.04)$. There was no statistically significant difference in the viral loads between subtype B and C-infected subjects.

We did not find any differences in gestational outcomes between the co-infected and non-co-infected patients or between those infected by different HIV-1 subtypes (Tables II, III). Vertical transmission of HIV was observed in only three children $(2.3 \%)$.

\section{TABLE I}

Prevalence of co-infections and cervical lesions in human immunodeficiency virus + pregnant women in southern Brazil

\begin{tabular}{lc}
\hline Co-infection/cervical lesion & $\begin{array}{c}\text { Prevalence } \\
\mathrm{n}(\%)\end{array}$ \\
\hline Hepatitis B & $3(2.3)$ \\
Syphilis & $4(3.1)$ \\
Hepatitis C & $14(10.8)$ \\
Human papillomavirus & $53(40.8)$ \\
Koilocytosis & $8(15.1)$ \\
Low grade intraepithelial lesion & $17(32)$ \\
High grade intraepithelial lesion/in situ carcinoma & $28(52.8)$ \\
\hline
\end{tabular}

\section{DISCUSSION}

A $10 \% \mathrm{HIV}-1 / \mathrm{HCV}$ co-infection prevalence was observed in our study, which is higher than the HCV prevalence among general pregnant women $(0.1 \%-2.7 \%)$ reported in other regions of Brazil (Costa et al. 2009, Lima \& Viana 2009). There are very few reports of $\mathrm{HIV} / \mathrm{HCV}$ co-infection in Brazil. A 5.5\% prevalence of this co-infection was reported among HIV-infected women in Rio de Janeiro (Joao et al. 2006) and a 20\% prevalence was found in another study in Porto Alegre (Kreitchmann et al. 2004), another city from southern Brazil. These studies, along with our results, provide evidence of a higher rate of $\mathrm{HCV}$ infection among HIV-positive subjects. One of the most important risk factors for $\mathrm{HIV} / \mathrm{HCV}$ co-infection is intravenous drug use (IDU) (Bollepalli et al. 2007), but this variable does not appear to influence the rates observed here, as the reported IDU was low (data not shown). On the other hand, HBsAg reactivity is also associated with HCV seropositivity (Landes et al. 2008), corroborating our finding that all $\mathrm{HBsAg}^{+}$patients in this study $(2.5 \%)$ were also infected with HCV. Vertical transmission of HCV in Brazil was reported to be between 2.5-5.6\% (Lima et al. 2004), but higher rates have been reported elsewhere (Marine-Barjoan et al. 2007). $\mathrm{HCV}$ viremia is an important risk factor for $\mathrm{HCV}$ vertical

TABLE II

Maternal and concept variables according to the presence of co-infections in human immunodeficiency virus (HIV)-1-positive pregnant women in southern Brazil

\begin{tabular}{|c|c|c|c|}
\hline Characteristic & Co-infected & Non-co-infected & $\mathrm{p}$ \\
\hline \multicolumn{4}{|l|}{$\operatorname{Race}[\mathrm{n}(\%)]$} \\
\hline Afro-descendant/mestizo & $17(29.2)$ & $15(22.4)$ & - \\
\hline White & $46(70.8)$ & $52(77.6)$ & 0.54 \\
\hline Age [mean (SD)] & $26.4(5.4)$ & $26.3(5.6)$ & 0.94 \\
\hline $\mathrm{HPV}^{+}$ & $25.3(4.8)$ & $27.0(5.9)$ & 0.09 \\
\hline Anti-HCV ${ }^{+}$ & $30.6(5.8)$ & $25.8(5.4)$ & 0.002 \\
\hline $\mathrm{HBsAg}^{+}$ & $31.3(1.1)$ & $26.2(5.7)$ & 0.12 \\
\hline $\mathrm{VDRL}^{+}$ & $28(3.5)$ & $26.3(5.7)$ & 0.55 \\
\hline $\mathrm{CD}^{+} \mathrm{T}$-cell counts $[$ mean $(\mathrm{SD})]$ & $563.7(323.6)$ & $632.5(372.8)$ & 0.25 \\
\hline HIV-1 viral load [mean log (SD)] & $1.54(1.71)$ & $0.97(1.55)$ & 0.04 \\
\hline \multicolumn{4}{|l|}{ HIV-1 subtype [n (\%)] } \\
\hline B & $11(22)$ & $17(35.4)$ & - \\
\hline $\mathrm{C}$ & $39(78)$ & $31(64.6)$ & 0.14 \\
\hline \multicolumn{4}{|l|}{ Rupture of membranes [n (\%)] } \\
\hline$\leq 4 \mathrm{~h}$ & $63(96.9)$ & $59(93.7)$ & - \\
\hline$>4 \mathrm{~h}$ & $2(3.1)$ & $4(6.3)$ & 0.60 \\
\hline \multicolumn{4}{|l|}{ Prematurity [n (\%)] } \\
\hline Yes & $6(10.2)$ & $2(3.3)$ & - \\
\hline No & $53(89.8)$ & $58(96.7)$ & 0.16 \\
\hline Mean birth weight [g (SD)] & $2863(547)$ & $2981(411)$ & 0.17 \\
\hline Apgar 1' [mean (SD)] & $7.7(1.49)$ & $8.1(1.1)$ & 0.11 \\
\hline Apgar 5' [mean (SD)] & $8.9(0.61)$ & $8.9(0.6)$ & 0.65 \\
\hline Capurro (weeks) [mean (SD)] & $38.7(1.5)$ & $38.9(1.3)$ & 0.55 \\
\hline
\end{tabular}

HBsAg: test for hepatitis B virus; HCV: hepatitis C virus; HPV: human papillomavirus; SD: standard deviation; VDRL: test for syphilis. 
transmission and HIV infection is an additional risk factor (Polis et al. 2007). Although we have shown that prolonged vaginal delivery and emergency $\mathrm{C}$-section may increase the risk for vertical transmission of $\mathrm{HCV}$, elective caesarean delivery is not yet generally indicated in cases of maternal HCV infection (McIntyre et al. 2006). Therefore, these results should be evaluated and additional studies should be performed to confirm our observation. Furthermore, co-infected patients have a higher risk for both hepatotoxicity and long-term liver damage upon antiretroviral treatment (Moodie et al. 2009).

We also found a high prevalence (40.1\%) of HIV-1/ HPV co-infection among pregnant women based on cervical smear cytology. Other studies in Brazil using more sensitive techniques, such as PCR, have found an HPV prevalence of $80-96 \%$ in HIV-infected pregnant women, which is higher than the rate observed in HIV-non-infected pregnant women (Jalil et al. 2009). A striking observation of our study was that over half of the patients presenting cervical cytology abnormalities had HSILs or cervical cancer, comprising an overall prevalence of HSILs or cervical cancer of $21 \%$. As far as we know, this is twice the rates described in different geographic populations of HIV-infected women (Dames et al. 2009). We do not know the reasons for this discrepancy in relation to other studies. High-risk HPV types in HIV-infected women have been correlated with lower $\mathrm{CD}^{+}{ }^{+} \mathrm{T}$-cell counts (Dames et al. 2009), but such a correlation was not feasible in our study because the CD4 measurements in our study were performed at 34 weeks of gestation, when most patients were already being treated with antiretrovirals. Further studies are ongoing to determine the risk factors for such rapid evolution of HPV infection in our study setting. Although the vertical transmission of HIV was low in this cohort, we could not assess the consequences of foetal exposure to HPV. The maternalfoetal transmission of HPV can occur not only through the genital tract during delivery, but also through the placenta (Rombaldi et al. 2008). One study suggests that HPV infection is associated with a slightly higher risk of foetal chromosome aberration (Eppel et al. 2000).

We found a reactive VDRL rate of $2.8 \%$ in our study population, which is lower than that described for HIVinfected women in Porto Alegre (8\%) (Kreitchmann et al. 2004). Maternal syphilis was associated with a 2.7fold increased risk of in utero HIV transmission (Thorne et al. 2008) and implementation of antenatal screening and treatment for syphilis will likely impact the rates of HIV vertical transmission. In 2007, the Brazilian Ministry of Health implemented an operational plan aimed at decreasing syphilis transmission in the country by $30 \%$ (MS 2007). For the southern region, where our study city is located, the expected incidence of syphilis per 1,000 live births was $1.7 \%$ at the end of 2001 .

TABLE III

Maternal and concept variables according to infecting HIV-1 subtype in human immunodeficiency virus (HIV)-1-positive pregnant women in southern Brazil

\begin{tabular}{|c|c|c|c|}
\hline Characteristics & Subtype B & Subtype C & $\mathrm{p}$ \\
\hline \multicolumn{4}{|l|}{ Race $[\mathrm{n}(\%)]$} \\
\hline Afro-descendant/mestizo & $10(33.3)$ & $15(20.8)$ & - \\
\hline White & $20(66.7)$ & $57(79.2)$ & 0.18 \\
\hline Age [mean (SD)] & $25.5(5.9)$ & $26.2(5.3)$ & 0.56 \\
\hline $\mathrm{CD}^{+} \mathrm{T}$-cell count $[$ mean $(\mathrm{SD})]$ & $700(335)$ & $547(340)$ & 0.04 \\
\hline HIV-1 viral load [mean log (SD)] & $1.03(1.5)$ & $1.5(1.7)$ & 0.18 \\
\hline Co-infection [n (\%)] & $11(22)$ & $39(78)$ & 0.14 \\
\hline $\mathrm{HPV}^{+}$ & $10(24.3)$ & $31(75.7)$ & 0.40 \\
\hline Anti-HCV ${ }^{+}$ & $1(11)$ & $8(89)$ & 0.22 \\
\hline $\mathrm{HBsAg}^{+}$ & $0(0)$ & $3(100)$ & - \\
\hline $\mathrm{VDRL}^{+}$ & $2(66.7)$ & $1(33.3)$ & 0.13 \\
\hline \multicolumn{4}{|l|}{ Rupture of membranes [n (\%)] } \\
\hline$\leq 4 \mathrm{~h}$ & $26(92.9)$ & $70(95.9)$ & - \\
\hline$>4 \mathrm{~h}$ & $2(7.1)$ & $3(4.1)$ & 0.82 \\
\hline \multicolumn{4}{|l|}{ Prematurity [n (\%)] } \\
\hline Yes & $2(8.9)$ & $6(8)$ & - \\
\hline No & $27(93.1)$ & $69(92)$ & 0.85 \\
\hline Mean birth weight [g (SD)] & $2981(492)$ & $2914(542)$ & 0.57 \\
\hline Apgar 1' [mean (SD)] & $8(1.55)$ & $7.85(1.37)$ & 0.57 \\
\hline Apgar 5' [mean (SD)] & $8.9(0.67)$ & $8.9(0.56)$ & 0.90 \\
\hline Capurro (weeks) [mean (SD)] & $39.1(1.3)$ & $38.7(1.4)$ & 0.26 \\
\hline
\end{tabular}

HBsAg: test for hepatitis B virus; HCV: hepatitis C virus; HPV: human papillomavirus; SD: standard deviation; VDRL: test for syphilis. 
Significant differences were not observed between the distinct HIV-1 viral subtypes and the presence of a co-infection $(\mathrm{p}=0.12)$, but $78 \%$ of the co-infected pregnant women were infected by HIV-1 subtype $\mathrm{C}$ and $22 \%$ were infected by subtype B. It is likely that the high prevalence of co-infected pregnant women carrying subtype $\mathrm{C}$ merely reflects the expansion of this variant in southern Brazil (Soares et al. 2005). Therefore, we conclude that the risk of co-infection is more dependent on high-risk sexual behaviour than HIV characteristics. In any case, an accumulation of cases in the next few years or the elaboration of multicentre studies in the southern region of Brazil will allow a more precise evaluation of the influence of HIV-1 subtypes on co-infections.

It is noteworthy to mention that patients carrying HIV-1 subtype $\mathrm{C}$ presented a lower mean $\mathrm{CD} 4^{+} \mathrm{T}$-cell count when compared to those infected by subtype B. This finding is in opposition to the findings of other studies, such as the work of Abraha et al. (2009) that stated a slower progression to AIDS in subtype C-infected subjects based on $\mathrm{CD}^{+} \mathrm{T}$-cell decline. Due to the low number of subtype B-infected patients in addition to the unknown time of HIV-1 infection of patients analysed, further studies are required to evaluate the influences of viral subtype on progression. We observed, however, that the presence of a co-infection did not alter the mean $\mathrm{CD} 4^{+} \mathrm{T}$-cell counts.

The plasma HIV-1 viral load of co-infected patients was greater than that of non-co-infected. Considering that most co-infected patients were HPV carriers, these results agree with the results of a study by Jalil et al. (2009), that associated the presence of HPV to high HIV loads.

No significant changes were observed in maternal and concepts outcomes despite the presence of co-infections or infection with different HIV-1 subtypes. This could be due to the follow-up, which includes support in improving adherence to treatment, antenatal care, monitoring of the appointments and a multidisciplinary team approach that these patients received at our reference HIV/AIDS hospital.

It was possible to observe that pregnant women, regardless of their serological status or infecting HIV-1 subtype, are still a vulnerable population to sexually transmitted diseases and possibly illicit drug use. Therefore, health policies as well as the intervention strategies carried out by the professionals in this area should focus on incentivising and educating patients about planned pregnancies and seeking antenatal services as early as possible. Moreover, patient access to antenatal services should be made easier and the quality of this service should be monitored. In this fashion, triage, diagnosis and follow-up of patients, as well as the treatment of infections, will be carried out more efficiently, which seems to be the best and simplest way to reduce paediatric infections and to assure better quality of life for both the mothers and their children.

\section{ACKNOWLEDGEMENTS}

To the School of Medicine, Laboratory of AIDS Support and the infectious diseases doctors and obstetricians from the Service AIDS/HIV of University Hospital Dr Miguel Riet Correa of FURG, and to Andreia Fiorani, for critical proofreading of the paper.

\section{REFERENCES}

Abraha A, Nankya IL, Gibson R, Demers K, Tebit DM, Johnston E, Katzenstein D, Siddiqui A, Herrera C, Fischetti L, Shattock RJ, Arts EJ 2009. CCR5- and CXCR4-tropic subtype C human immunodeficiency virus type 1 isolates have a lower level of pathogenic fitness than other dominant group M subtypes: implications for the epidemic. J Virol 83: 5592-5605.

Alberti A, Clumeck N, Collins S, Gerlich W, Lundgren J, Palu G, Reiss P, Thiebaut R, Weiland O, Yazdanpanah Y, Zeuzem S 2005. Short statement of the first European Consensus Conference on the Treatment of Chronic Hepatitis B and C in HIV Co-infected Patients. J Hepatol 42: 615-624.

Bollepalli S, Mathieson K, Bay C, Hillier A, Post J, Van Thiel DH, Nadir A 2007. Prevalence of risk factors for hepatitis C virus in HIV-infected and HIV/hepatitis C virus-coinfected patients. Sex Transm Dis 34: 367-370.

Costa ZB, Machado GC, Avelino MM, Gomes Filho C, Macedo Filho JV, Minuzzi AL, Turchi MD, Stefani MM, de Souza WV, Martelli CM 2009. Prevalence and risk factors for hepatitis C and HIV-1 infections among pregnant women in central Brazil. BMC Infect Dis 9: 116.

Dames DN, Ragin C, Griffith-Bowe A, Gomez P, Butler R 2009. The prevalence of cervical cytology abnormalities and human papillomavirus in women infected with the human immunodeficiency virus. Infect Agent Cancer 4 (Suppl. 1): S8.

Eppel W, Worda C, Frigo P, Ulm M, Kucera E, Czerwenka K 2000. Human papillomavirus in the cervix and placenta. Obstet Gynecol 96: 337-341.

Franceschi S, Jaffe H 2007. Cervical cancer screening of women living with HIV infection: a must in the era of antiretroviral therapy. Clin Infect Dis 45: 510-513.

Jalil EM, Duarte G, El Beitune P, Simoes RT, dos Santos Melli PP, Quintana SM 2009. High prevalence of human papillomavirus infection among Brazilian pregnant women with and without human immunodeficiency virus type 12009 . Obstet Gynecol Int 2009: 485423.

Joao EC, Calvet GA, Menezes JA, D’Ippolito MM, Cruz ML, Salgado LA, Matos HJ 2006. Nevirapine toxicity in a cohort of HIV-1-infected pregnant women. American J Obstet Gynecol 194: 199-202.

Kiwanuka N, Laeyendecker O, Robb M, Kigozi G, Arroyo M, McCutchan F, Eller LA, Eller M, Makumbi F, Birx D, Wabwire-Mangen F, Serwadda D, Sewankambo NK, Quinn TC, Wawer M, Gray R 2008. Effect of human immunodeficiency virus type 1 (HIV-1) subtype on disease progression in persons from Rakai, Uganda, with incident HIV-1 infection. J Infect Dis 197: 707-713.

Kreitchmann R, Fuchs SC, Suffert T, Preussler G 2004. Perinatal HIV-1 transmission among low income women participants in the HIV/AIDS Control Program in Southern Brazil: a cohort study. BJOG 111: 579-584.

Landes M, Newell ML, Barlow P, Fiore S, Malyuta R, Martinelli P, Posokhova S, Savasi V, Semenenko I, Stelmah A, Tibaldi C, Thorne C 2008. Hepatitis B or hepatitis C coinfection in HIVinfected pregnant women in Europe. HIV Med 9: 526-534.

Lima LH, Viana MC 2009. Prevalence and risk factors for HIV, syphilis, hepatitis B, hepatitis C and HTLV-I/II infection in low-income postpartum and pregnant women in greater metropolitan Vitória, Espirito Santo state, Brazil. Cad Saude Publica 25: 668-676.

Lima MP, Pedro RJ, Rocha MD 2004. Mother-to-infant transmission of hepatitis C virus (HCV) in Brazil. J Trop Pediatr 50: 236-238.

Marine-Barjoan E, Berrebi A, Giordanengo V, Favre SF, Haas H, Moreigne M, Izopet J, Tricoire J, Tran A, Pradier C, Bongain A 2007. HCV/HIV co-infection, HCV viral load and mode of deliv- 
ery: risk factors for mother-to-child transmission of hepatitis $\mathrm{C}$ virus? AIDS 21: 1811-1815.

McIntyre PG, Tosh K, McGuire W 2006. Caesarean section versus vaginal delivery for preventing mother-to-infant hepatitis $\mathrm{C}$ virus transmission. Cochrane Database Syst Rev: CD005546.

Moodie EE, Pant Pai N, Klein MB 2009. Is antiretroviral therapy causing long-term liver damage? A comparative analysis of HIVmono-infected and HIV/hepatitis C co-infected cohorts. PLoS ONE 4: e4517.

MS - Ministério da Saúde do Brasil 2007. Plano operacional para redução da transmissão vertical do HIV e da sífilis. Available from: aids.gov.br.

MS - Ministério da Saúde do Brasil 2010a. Boletim epidemiológico de DST e AIDS. Available from: aids.gov.br.

MS - Ministério da Saúde do Brasil 2010b. Recomendações para profilaxia da transmissão vertical do HIV e terapia antirretroviral em gestantes. Available from: aids.gov.br.

Mwapasa V, Rogerson SJ, Kwiek JJ, Wilson PE, Milner D, Molyneux ME, Kamwendo DD, Tadesse E, Chaluluka E, Meshnick SR 2006. Maternal syphilis infection is associated with increased risk of mother-to-child transmission of HIV in Malawi. AIDS 20: 1869-1877.

Polis CB, Shah SN, Johnson KE, Gupta A 2007. Impact of maternal HIV coinfection on the vertical transmission of hepatitis $C$ virus: a meta-analysis. Clin Infect Dis 44: 1123-1131.
Poveda E, de Mendoza C, Parkin N, Choe S, Garcia-Gasco P, Corral A, Soriano V 2008. Evidence for different susceptibility to tipranavir and darunavir in patients infected with distinct HIV-1 subtypes. AIDS 22: 611-616.

Renjifo B, Gilbert P, Chaplin B, Msamanga G, Mwakagile D, Fawzi W, Essex M 2004. Preferential in-utero transmission of HIV-1 subtype C as compared to HIV-1 subtype A or D. AIDS 18: 1629-1636.

Rombaldi RL, Serafini EP, Mandelli J, Zimmermann E, Losquiavo KP 2008. Transplacental transmission of human papillomavirus. Virol J 5: 106

Soares EA, Martinez AM, Souza TM, Santos AF, Da Hora V, Silveira J, Bastos FI, Tanuri A, Soares MA 2005. HIV-1 subtype C dissemination in southern Brazil. AIDS 19 (Suppl. 4): S81-S86.

Soriano V, Barreiro P, Nunez M 2006. Management of chronic hepatitis B and C in HIV-coinfected patients. J Antimicrob Chemother 57: 815-818.

Tamura K, Dudley J, Nei M, Kumar S 2007. MEGA4: Molecular Evolutionary Genetics Analysis (MEGA) software version 4.0. Mol Biol Evol 24: 1596-1599.

Thorne C, Malyuta R, Semenenko I, Pilipenko T, Stelmah A, Posokhova $\mathrm{S}$, Newell ML 2008. Mother-to-child transmission risk is increased among HIV-infected pregnant women in Ukraine with serological test results positive for syphilis. Clin Infect Dis 47: 1114-1115.

WHO - World Health Organization 2010. HIV/AIDS epidemic update 2010. Available from: aids.gov.br. 